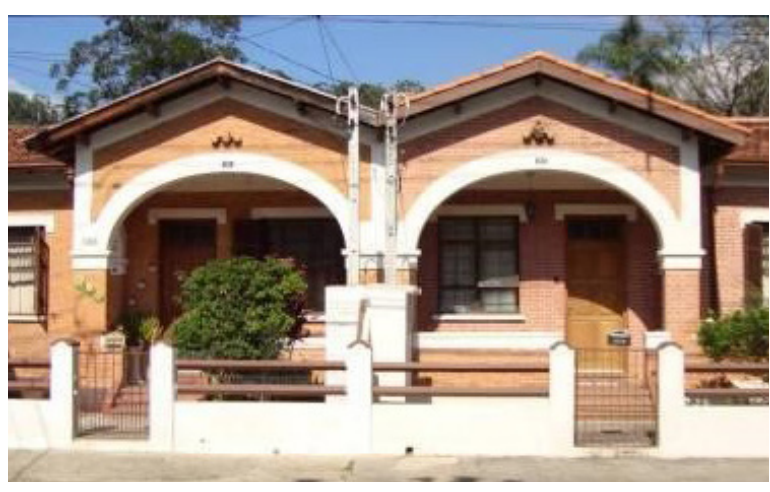

*Bacharel e Licenciada em História pela Universidade de São Paulo, especialista em Gestão do Patrimônio e Cultura pelo Centro Universitário Assunção, Especialista em Investigación en Historia Reciente: desafíos conceptuales $y$ disciplinares pelo Centro Argentino de Información Científica y Tecnológica, Argentina; Mestre em História Social pela Universidade de São Paulo; Doutoranda em História na Universidade Estadual de Campinas. Historiadora da Unidade de Preservação do Patrimônio Histórico da Secretaria da Cultura do Estado de São Paulo. Membro do Comitê Editorial da Annablume, linha "Urbanidades: Territórios e Urbanismos". Membro do Conselho Internacional de Monumentos e Sítios -Brasil.

\title{
Tecendo a história de São Paulo: tecelagens como patrimônio cultural
}

\author{
Weaving the history of São Paulo: textille factories as Cultural Heritage
}

Deborah Regina Leal Neves*

\section{Resumo}

O artigo apresenta o resultado do trabalho de pesquisa sobre seis indústrias têxteis instaladas em três regiões administrativas do estado de São Paulo entre o final do século XIX e a década de 1920. Tais edifícios, desprovidos de sua função original, foram objeto de pedido de tombamento ao Conselho de Defesa do Patrimônio Histórico, Artístico, Arqueológico e Turístico do Estado de São Paulo (CONDEPHAAT) por cidadãos preocupados em preservar as múltiplas memórias ativadas pelos espaços. A partir de critérios construídos pela área técnica da Unidade de Preservação do Patrimônio Histórico (UPPH) - que subsidia as decisões do CONDEPHAAT -, quatro unidades foram reconhecidas como patrimônio cultural do estado. Trata-se de exemplares com relevância para a compreensão das relações de trabalho, da arquitetura industrial, do desenvolvimento urbano, econômico e tecnológico a partir do setor têxtil, o mais pujante do país à época. Atualmente, o uso das edificações está destinado a atividades diversas, ressiginificando sua presença na paisagem e no imaginário coletivo, provocando o debate sobre como integrar antigas estruturas às novas necessidades das cidades.

Palavras-chave: Patrimônio Industrial. Tecelagem. Tombamento.

\section{Abstract}

his scientific article presents the research results about six textile factories installed in three different administrative regions of Sao Paulo State between ending of XIX Century and 1920's. These buildings, devoid of their original function generally since 1980's, was recognize as cultural heritage by CONDEPHAAT (institution responsible for developing cultural heritage policy in Sao Paulo) after citizens compromised in keeping alive multiples memories related to these buildings require it to list them. Based on criteria developed by Cultural Heritage Department's technicians, four plants were declared State's Cultural Heritage. It is important samples which are relevant to understand work relations, industrial architecture, and urban, economic and technology development from the textile sector - the most powerful in the country at that time. Currently, the buildings are being used with other functions, resignifying their presence in landscape and inside collective imaginary, sparking debate on how to integrate old structures into the new needs of contemporary cities.

Keywords: Industrial Heritage. Textile Factory. Cultural Heritage Recognition. 
1. A Guerra de Secessão foi desencadeada nos Estados Unidos da América em decorrência de uma tentativa separatista dos estados do Alabama, Carolina do Sul, Flórida, Georgia, Louisiana, Mississipi e Texas, seguidos por Virgínia, Arkansas, Carolina do Norte e Tennessee para formar os Estados Confederados da América. A região, de característica predominantemente agrária, em especial o plantio do algodão, tabaco e cana-de- -açúcar, se opunha à abolição da escravidão de pessoas negras, mão de obra nas fazendas. A tentativa de criar um novo país levou a uma guerra civil que durou cinco anos, com a derrota dos confederados e a morte e desaparecimento mais de 620 mil pessoas. O plantio de algodão ficou bastante prejudicado durante o conflito, favorecendo o plantio e o comércio em outros países, como o Brasil.
C

onsiderando que o início da atividade industrial no Brasil é tardia em relação aos países europeus e mesmo das Américas - especialmente em virtude do Tratado de Methuen entre outros dispositivos legais da Coroa -, é somente em fins do século XIX que os primeiros empreendimentos industriais começam a se desenvolver no país, especialmente após a Proclamação da República (1889). Até então, apenas atividades isoladas e bastante precárias tiveram início, porém em escala de atendimento local e sem expressividade econômica (SANT'ANNA, 1944; MOTA, 2003).

$A$ atividade industrial foi impulsionada principalmente pelo capital oriundo do comércio do café, muitas vezes associado ao capital estrangeiro, seja por investimento direto ou por meio de empréstimos em bancos. Facilitada pela malha ferroviária implementada ao fim do século XIX e incrementada desde então, as fábricas de tecidos predominaram na paisagem industrial brasileira, especialmente favorecida pela Guerra da Secessão (1861-1865) ${ }^{1}$, sendo o estado de São Paulo um dos principais locais de desenvolvimento desta indústria (PRADO JUNIOR, 2012; DEAN, 1971).

Os importadores desempenharam papel fundamental na criação da indústria nacional, uma vez que as instalações fabris dependiam de itens importados para sua constituição (equipamentos, estruturas metálicas, mecanismos etc.). O conhecimento dos meandros do mercado, o acesso ao crédito e aos canais para escoamento dos produtos acabados possibilitou que inúmeros importadores convertessem suas agências em empresas industriais frente ao crescimento da manufatura nacional e às possibilidades no ramo, até então inexistente (DEAN, 1971; RIBEI$\mathrm{RO}, 1988)$. 
Em São Paulo, o lucro advindo do capital oriundo do plantio e comércio cafeeiro foi grande responsável pelos recursos necessários à implantação das primeiras indústrias (ainda que para atender à produção cafeeira, como as fábricas de sacos de juta). É por essa razão que as sociedades anônimas se constituíram como forma mais comum de estabelecimento de empresas, de modo que em $1907,58 \%$ do total do capital das indústrias no Brasil estavam assim organizadas, favorecendo a concentração e a centralização do capital da grande indústria neste estado (DE DECCA, 2004, p.146).

A historiografia demonstra que o algodão surgiu como um dos circuitos mais importantes da teia produtiva desenvolvida pelo café. Tratava-se de uma antiga e tradicional atividade agrícola em São Paulo - como em outras regiões do país, sobretudo Norte e Nordeste -, mas de pequena escala e destinada à confecção de tecidos simples de algodão, linho e juta para roupas rústicas, rendas, redes, mosquiteiros, cordas, cordões e sacos feitos em fusos, rocas e teares manuais, operados por artesãos das próprias fazendas ou por fiandeiras e tecelões em pequenas oficinas independentes nas cidades. Tinha sido, até então, uma atividade mais ligada à economia de subsistência local, ao comércio regional do que ao main stream da economia brasileira (TEIXEI$\mathrm{RA}, 2007$ ).
Às condições econômicas do estado, aliaram-se os recursos naturais favoráveis e fartamente disponíveis, propiciando potencial de geração de energia hidráulica e depois elétrica. Assim, do ponto de vista da geografia industrial, podem-se destacar dois elementos decisivos para a localização das fábricas: as ferrovias (transporte de matérias-primas, máquinas e trabalhadores imigrantes; transporte dos bens industriais produzidos) e os rios que, além da função de transporte, passaram a ser usados como fontes de energia hidráulica e hidrelétrica e, no outro extremo, como depositários dos detritos industriais, especialmente no caso dos curtumes, fábricas de papel e tecelagens.

Como o mercado do Estado de São Paulo consumia tanto artigos de luxo como populares, o cenário era conveniente ao desenvolvimento de pequenas e grandes fábricas, estas últimas em maior quantidade no interior paulista. O critério de definição do porte das empresas analisadas foi aquele trazido por Belanga (2006, p.51) e associado ao estudo de PEARSE (1921, p.210), incorporados ao estudo na UPPH:

O tamanho das empresas foi definido a partir dos seguintes cortes: pequeno porte, firmas com capital até 30 contos de réis, 1 a 10 empregados e força motriz até 25 cavalos de potência instalada; médio porte, firmas com capital entre 30 e 200 contos de réis, 11 a 100 empregados e força motriz de 26 a 100 cavalos de potência instalada; grande porte, firmas com 
capital acima de 200 contos de réis, mais de 100 empregados e força motriz acima de 100 cavalos de potência instalada.

A partir dos estudos, identificou-se a predominância de empresas de grande porte e, portanto, a plena separação entre capital e trabalho. Assim, nesse setor, os proletários já se achavam inteiramente submetidos à dinâmica própria da maquinaria instalada na fábrica, razão pela qual foi analisada também a relação entre patrões e empregados, capital e trabalhador. Ribeiro enfatiza que os estabelecimentos têxteis instalados nas últimas três décadas do século XIX empregavam máquinas de tecer, cuja organização entre elas conferia unidade à organização produtiva e conferia ao homem uma posição secundária na cadeia, figurando apenas como operador e não mais como agente produtivo (RIBEIRO, 1988, p.32). É o que Marx classificou como "alienação do trabalho", que ocorre quando o homem perde sua ferramenta e o poder de produção e passa a ser apenas uma engrenagem de todo um sistema amplo e mecanizado. Para atender às necessidades de produção, o edifício que abriga a atividade de trabalho deixa de ser pequenas oficinas ou cômodos improvisados e passam a ser locais de grandes dimensões e adequados à acomodação de numerosas máquinas e trabalhadores, associados a fontes energéticas próprias, mecânicas e posteriormente, hidrelétricas.
A grande indústria têxtil representava, assim, o lado mais avançado das relações capitalistas de produção no Brasil: era o setor que apresentava os maiores índices de concentração de capital, força de trabalho e força motriz por unidade de produção, além de alcançar as maiores taxas de valor da produção. Em 1928, São Paulo concentrava $64 \%$ do capital investido e $60 \%$ dos operários empregados; o interior contava com $40 \%$ desses operários, com a maioria empregada em indústrias algodoeiras (LOUREIRO, 2006, p.39).

$\mathrm{O}$ estudo das tecelagens demonstrou ainda que o movimento operário originado nas fábricas de tecidos é responsável por parcela significativa das conquistas de direitos trabalhistas que ainda perduram no presente. Como a maior parte da mão de obra empregada na indústria estava justamente no setor têxtil, foram as organizações de trabalhadores ou de sindicatos deste setor que reivindicaram e conquistaram avanços nas relações de trabalho. Ao contrário do que comumente se imagina, "(...) longe de terem sido apenas uma dádiva do Estado, os direitos trabalhistas tiveram de ser 'tecidos' no plano da realidade pelos próprios trabalhadores" (LOUREIRO, 2011, p.281).

A formação do operariado paulista se deu especialmente em função da Lei de Terras (1850), que facilitou aos estrangeiros a aquisição de terras no país. Dessa forma, aqueles que possuíam condições financeiras para a aquisição de terras formaram colônias em que outros conterrâneos - 
em especial italianos - se instalaram para trabaIhar na lavoura; saliente-se que a população livre brasileira também compôs mão de obra nesses empreendimentos. Com o declínio da produção agrícola, a mão de obra essencialmente rural passa a migrar para a cidade buscando trabalho nas indústrias, somando-se ao contingente que continuava a migrar da Europa diretamente para a área urbana. De acordo com Hardman e Leonardi (1991, p.141)

Em 1912, segundo o Boletim Estadual do Trabalho, dos 10.184 operários têxteis existentes na capital do Estado, 6.044 eram italianos; 824, portugueses; 338, espanhóis; 210, sírios; 50, alemães; 13 japoneses; outros estrangeiros, 862, o que dava um total de imigrantes correspondente a $82 \%$ da categoria. Os brasileiros natos eram em número de 1843, ou seja, minoritários (18\%).

Parte destes trabalhadores era oriunda de indústrias em seus países de origem e, somados aos trabalhadores brasileiros, desenvolveram ideias libertárias - em geral de inspiração socialista, comunista e anarquista - organizando-se para representar seus interesses. Logo nos primeiros anos do século $X X$, surgiram os primeiros sindicatos e associações de trabalhadores, que reivindicavam direitos aos patrões. Isso porque a relação entre operários e patrões era conflituosa, especialmente por conta das longas jornadas de trabalho, que chegavam a durar entre 12 e 16 horas, com mão de obra predominantemente feminina e infantil, que recebiam remuneração menor pelo trabalho executado. Não raro, as instalações eram insalubres e suscetíveis a acidentes, nunca indenizados. As condições impróprias levaram os trabalhadores que, no dia-a-dia experimentavam a vivência coletiva, a se organizarem cada vez mais, até que em 1907 uma nova lei garantiu aos trabalhadores o direito de associação, assegurando que as organizações sindicais não seriam submetidas ao controle estatal.

Decorrente desta organização, as grandes greves operárias do século $X X$ tiveram, em sua maioria, os trabalhadores têxteis como protagonistas. É o caso das greves de 1907, 1910 e da Grande Greve de 1917, iniciada nas ruas do Brás e intensificada após a morte do operário anarquista de origem espanhola José Martinez. Cerca de 400 operários do Cotonifício Crespi decidiram paralisar o trabalho depois de a diretoria ter rejeitado o pedido de aumento salarial entre 15 e $20 \%$ e abolir a extensão da carga horária noturna de trabalho (BIONDI, 2009). Essa greve tomou proporções inimagináveis mobilizando ao menos 50.000 operários - ou 12,5\% da população da cidade de São Paulo à época - e é tratada por boa parte da bibliografia sobre o tema como um paradigma na história da organização dos trabalhadores. Se antes havia pouca organização, a partir de então as associações operárias e sindicais desenvolveram estrutura consistente, uma sólida rede de mobilização entre diferentes fábricas e de diferentes categorias, conseguindo exercer pressão sobre os grupos empresariais. 
Isso porque a partir da Greve de 1917, organizaram-se o Comitê de Defesa Proletária, liderado por anarcossindicalistas, além de imprensa operária especializada (HARDMAN; LEONARDI, 1991), o Comitê Popular de Agitação contra a Exploração de Menores Operários, cujo programa se voltava ao combate aos maus-tratos sofridos pelos menores, aplicados pelos mestres e contramestres e a União dos Operários em Fábricas de Tecidos (UOFT). Esta última foi a principal responsável por reivindicações como melhoria nos salários e nas condições de trabalho, regulamentação do trabaIho feminino e do menor, além do reconhecimento oficial, pelo patronato, do direito das associações operárias representarem os trabalhadores através do Acordo Coletivo de Trabalho.

A reação dos industriais à organização dos trabaIhadores foi a criação do Centro dos Industriais de Fiação e Tecelagem de São Paulo (CIFT), apoiado pela grande imprensa e Governo, especialmente por meio das forças de repressão. Essa simbiose entre interesses de industriais e do Estado resultou em dura e organizada repressão aos movimentos de trabalhadores - especialmente com a criação do Dops em 1924 - até seu "disciplinamento" durante o Estado Novo; saliente-se que, no entanto, a força dos sindicatos perdurou com bastante relevância até a década de 1990, quando as relações de trabalho foram significativamente modificadas.
A grande dificuldade para construir a história do movimento dos trabalhadores em cada fábrica está nas fontes disponíveis para elaborar os pareceres técnicos que fundamentam as opiniões encaminhadas ao Conselho. Para a compreensão mais geral, estão disponíveis acervos de jornais operários e outros documentos associativos em bancos de dados digitais do Arquivo do Estado de São Paulo, do Arquivo Edgard Leuenroth (AEL-UNICAMP), do CEDEM-UNESP, do CEDEC-PUC e do CECULT-UNICAMP. Através desses acervos diretamente relacionados ao movimento operário é possível ter ideia das reivindicações e das condições de trabalho. A bibliografia é vasta e se apoiou em relatórios do Ministério do TrabaIho e em documentos patronais em que é relatado o ponto de vista do empresariado acerca das reivindicações e as ações para coibir movimentos paredistas. Mas a análise da mobilização trabalhista em cada uma das fábricas em estudo na UPPH foi bastante prejudicada, seja pelo tempo disponível para apresentar parecer conclusivo, seja pelos recursos - materiais, humanos e financeiros - disponíveis para a pesquisa, e mesmo pela disponibilidade de fontes. Assim, o estudo se pautou pela análise ampla sobre as mobilizações mais contundentes do operariado têxtil paulista e em cada parecer individual apresentou-se referências específicas de cada indústria na medida em que foram encontradas, tendo em vista que não há homogeneidade na disponibilidade de informações sobre as indústrias estudadas. 
2. No RJ: Fábrica Cometa e vila operária, Companhia Petropolitana de Tecidos e Fábrica São Pedro de Alcântara (Petrópolis) e Fábrica de Pólvora e seu antigo portão (Rio de Janeiro); na BA: Engenho Matoim e Engenho Freguesia (Candeias); em MG: Fábrica de Ferro Patriótica (Ouro Preto); PB: Fábrica de Vinho Tito Silva (João Pessoa); no MA: Fábrica Santa Amélia (São Luís); em SP: Sesc Pompeia (São Paulo), Fábrica de Chá Amaya, Fábrica de Chá Kawagiri e Fábrica de Chá Shimizu(Registro); no PI: Fábrica de Manteiga e Queijo (Campinas do Piauí).

Ruínas do Engenho do Rio Quilombo e Ruínas do Engenho dos Erasmos (Santos); Real Fábrica de Ferro de São João de Ipanema (Iperó); Ruínas do Engenho da Lagoinha (Ubatuba); Casarão Do Chá (Mogi das Cruzes); Usina Hidrelétrica de Corumbataí (Rio Claro); Fábrica de Tecidos São Luís (Itu); Matadouro de Vila Mariana, Vila Maria Zélia, Complexo do
Gasômetro, Indústrias Reunidas Francisco Matarazzo, Moinho Minetti e Gamba, Fábrica de Tecidos Labor, Tecelagem de Seda Ítalo-Brasileira, Moinho Matarazzo (São Paulo); Kaigai Kogyo Kabushiki Kaisha (Registro); Destilaria Central (Lençois Paulista); Manufatura de Tapetes Santa Helena (Jacarei); Indústrias Reunidas Francisco Matarazzo (Marília); Fábrica Santa Adélia e Indústrias Têxteis São Martinho (Tatuí); Cervejaria Paulista (Ribeirão Preto); Fábrica Swift Armour (São José do Rio Preto) Fábrica, Vila Operária e Usina de Energia Vila Carioba (Americana); Fábrica de Tecidos Brasital (Salto); Engenho Central de Piracicaba (Piracicaba); Recinto de Exposições Agropecuárias (Barretos); Fábrica Gessy Lever (Valinhos), Fábrica Lidgerwood (Campinas) e Antiga Fábrica de Sal - Molino di Semoli Fratelli Maciotta (Ribeirão Pires) além das quatro tecelagens abordadas neste artigo.
Diante da complexidade da indústria têxtil na constituição da sociedade paulista, é possível compreender a sensibilidade da população diante dos fechamentos das principais fábricas nas décadas de 1970 e 1980. O fechamento destes grandes complexos industriais, além de gerar enorme número de demissões, falências e prejuízos a credores e trabalhadores, legou às cidades grandes imóveis que não mais ditavam o ritmo do cotidiano com seus apitos pontuais, tornando-se um problema urbanístico pelo abandono. Locais estes que permaneceram por décadas na paisagem e no imaginário coletivo, suscitando grande valor afetivo nos habitantes de bairros ou cidades onde estão instaladas.

Com o intuito de impedir o apagamento da memória - já que os complexos industriais estavam ameaçados de demolição para dar lugar a avenidas ou empreendimentos comerciais e/ou residenciais que não aproveitariam a construção existente -, movimentos civis, até mesmo de ex-funcionários destas fábricas demandaram ao CONDEPHAAT a preservação destes edifícios que sediaram, muitas vezes, o único emprego de suas vidas e de suas famílias. Motivados pela ausência de práticas de preservação patrimonial em suas cidades por absoluta ausência de força ou legitimidade política de órgãos de preservação municipal, a alternativa residia no órgão estadual, possuidor de algum prestígio na sociedade e relativa independência das dinâmicas políticas e econômicas locais.
A congruência entre período de atividade, localização, importância no desenvolvimento econômico do estado e quantidade expressiva de pedidos de tombamento de tecelagem fez com que o Grupo de Estudos de Inventários (GEI) da UPPH tratasse dessas indústrias como um conjunto a ser analisado sob os mesmos parâmetros, a fim de identificar a pertinência da preservação em âmbito estadual. Sendo assim, o estudo como conjunto temático serviu, para além do tombamento, também como um inventário do passado têxtil do Estado de São Paulo, permitindo a ampliação do conhecimento deste setor bastante abordado por estudos acadêmicos, mas até então sem reconhecimento como patrimônio cultural em algumas cidades chave para o ramo, como São Paulo e Sorocaba, por exemplo.

Não obstante a importância da indústria de um modo geral, mas em especial a têxtil para a economia brasileira, o patrimônio industrial tem sido objeto de recente e tímida preservação, inaugurado em âmbito federal com o tombamento da Real Fábrica de Ferro Ipanema pelo IPHAN em 1964, quase trinta anos depois de criado o serviço. A prática de preservação desses equipamentos industriais ainda é incipiente: o IPHAN reconhece apenas 14 bens $^{2}$ desta natureza como patrimônio cultural e, exceto o Sesc Pompeia - reconhecido mais pela intervenção de Lina Bo Bardi que pela atividade fabril -, boa parte teve as atividades encerradas ainda no século XIX, vinculadas ao período imperial. 
Em contrapartida, o estado de São Paulo, maior expoente industrial do país no século $X X$, já possui uma ampla e variada gama de edifícios industriais preservados, além daqueles aqui abordados. Excluídos os bens ligados à ferrovia (estações, pátios e oficinas), o CONDEPHAAT tombou 34 bens ligados à atividade industrial até o ano de 2018 , dos quais 12 bens estão ligados diretamente à atividade têxtil - ou $35 \%$ do total de tombamentos. Dessa forma, de todos os bens industriais inventariados pelo CONDEPHAAT (atualmente são 77 processos, incluindo ruínas), 20 estão relacionados à indústria de tecidos, correspondendo a $26 \%$ do total.

As fábricas de tecidos estudadas entre 2010 e 2014 na UPPH correspondem ao período compreendido entre os anos finais do século XIX e 1920, considerado por Stein (1979) como a "idade de ouro" para a indústria têxtil. A partir do estudo foi possível classificá-lo em duas fases: a primeira, ocorrida entre o fim do século XIX e 1910; a segunda é o período de consolidação, entre 1910 e 1925, quando a produção de tecidos entrou em crise. Entre os pontos comuns está a dimensão das plantas das unidades fabris, que ocupam, invariavelmente, grandes lotes nas cidades. O processo de produção, dividido em diversas etapas, exigia que os espaços fossem amplos - para a circulação de ar, entrada de luz e para abrigar todas as máquinas e trabalhadores envolvidos no fabrico. Grande parte das indústrias de São Paulo era composta por fiações e tecelagem, isso é, tratavam o algodão bruto ou em rama transformando-o em fio a partir do qual era fabricado o tecido. Outras, em menor escala, eram apenas tecelagens, ou seja, compravam o fio - nacional ou importado - para produzir tecidos.

A solução de arquitetura para atender Código Sanitário de 1894 (SÃO PAULO. Decreto n 233 de 02/03/1894) deveria suprir deficiências de iluminação e ventilação, principalmente, resolvidas com a construção de lanternins, sheds com vidraças móveis no lado de sombra e, em alguns casos, ventilação artificial. Dessa forma, a historiografia tende dividir a forma física das indústrias em duas tipologias, "colonial brasileiro" e "britânico manchesteriano" (HARDMAN; LEONARDI, 1991, 133-134). Para os autores, os modelos se explicam da seguinte forma:

a) Colonial brasileiro: fábricas construídas no Império, com tipologia semelhante às casas grandes de fazendas, produção de algodão em terreno próprio, acumulando o capital agrícola e industrial na mesma atividade. Como exemplo, citam as fábricas São Luís (Itu, 1869), São Bento (Jundiaí, 1874) e São Martinho (Tatuí,1881);

b) Britânico Manchesteriano: fábricas surgidas ao final do século XIX e no século $X X$, cuja fachada era de tijolos de barro aparente, simetria de planos e estrutu- 
ra sóbria. Também se caracteriza por vários edifícios, com alguns destacados por dois ou três pavimentos. Como exemplo, a Brasital (Salto) e a Labor (São Paulo);

b.1) Estilo Alemão: tijolos aparentes, construções altas e compactas, com dois ou mais andares e janelas pequenas. Como exemplo: Fábrica de Tecidos Carioba, em Americana.

Acrescentou-se à definição dos autores a produção de estabelecimentos industriais pós década de 1920, em que a padronização de elementos e a utilização de concreto e materiais pré-fabricados permitiram a rápida modificação do uso dos edifícios. Possuem poucas aberturas laterais e de ventilação natural, procurando diminuir a incidência de luz solar sobre a fibra de algodão, que "prejudicava" o produto. Esse traço é característico da Argos Industrial S. A. de Jundiaí, que possuía edifícios "manchesterianos" do início do século XX combinados com outros padronizados datados da década de 1940, mas que só mantém os últimos com mais destaque, já que sua parte mais antiga foi demolida para a duplicação de uma avenida que sequer utilizou o espaço pretendido para a obra.

O volume de processos em estudo no GEl revela a predominância das características "manchesterianas", possivelmente por duas razões: a maioria das indústrias foi construída já na República e após o Código Sanitário de 1894, que exigia metragem mínima de $8 \mathrm{~m} 3$ para cada empregado, preferência para iluminação elétrica, exigência de pintura anual, abastecimento de água, esgoto, banheiros (um para cada 20 empregados) e entre até 1925; as edificações posteriores estudadas eram parte de ampliação das instalações pré-existentes.

A forma de avaliar cada um dos pedidos pautou-se pela adoção de critérios suficientemente amplos para abranger a diversidade do estado e da própria atividade industrial, mas limitava o reconhecimento como patrimônio a algumas indústrias, elegendo representantes de forma metonímica. Os critérios adotados foram os seguintes, sempre da perspectiva estadual e em consonância com as diretrizes preconizadas pelo The International Commitee for the Conservation of the Industrial Heritage (TICCIH), especialmente os presentes na Carta de Nizhny Tagil:

- Pioneirismo técnico/tecnológico: a indústria têxtil era disseminada pelo país, e concentrada no estado de São Paulo. Portanto, um critério adotado para definição de importância é apresentação de algum pioneirismo na técnica empregada seja nos equipamentos (tecnológico), seja na atuação do homem (técnico) que desencadeou alterações em toda a indústria têxtil, ou seja, que tenha incrementado o método existente e comumente empregado. 
- Inserção no cenário econômico - trata-se de identificar a relevância para o desenvolvimento do setor - quantidade de fusos, teares, emprego de equipamentos a vapor ou elétricos, capacidade produtiva, potência em HP -, e sua importância para a economia (quantidade de empregados, volume de capital aplicado e investido, desdobramento em outras atividades como fabricação de óleos, por exemplo, capilaridade pelo território, exclusividade de produção de determinado produto);

- Mobilização operária - greves, manifestações, conquista de direitos trabalhistas, organizações sindicais, mudanças nas relações entre empregado e patrão (ou capital), que representaram marcos ou mudanças importantes para a história do trabalho;

- Inovação tecnológica ou de produtos dentro de seu contexto - trata-se de emprego de técnicas ou equipamentos diferenciados, ou ainda de inovação em produtos, destacando a empresa no contexto estadual;

- Representante de políticas do Estado: inversão de capital do estado na indústria; conexão com políticas de incentivo industrial, povoamento, instalação de colônias, escolas/cursos de capacitação profissional, investimento estatal no setor primário para o fomento do setor industrial etc.;
- Promoção de mudanças no hábito/cultura/cotidiano dos trabalhadores e do contexto geográfico - isso é, quando a instalação da indústria ou a sua presença inaugure equipamentos em locais desprovidos anteriormente, migração de mão de obra de outros locais que modifiquem a identidade cultural com e do local, mudanças culturais como cinemas, teatros, formas de organização social etc.;

- Critérios arquitetônicos urbanísticos considerados para a eleição de bens: importância na configuração urbana, destaque na paisagem, adoção de sistemas construtivos diferenciados.

As fontes utilizadas para a pesquisa sobre cada uma destas indústrias compreenderam: publicações em jornais, atas de assembleias, Diário Oficial do Estado e da União, fotografias de acervos históricos, documentos arquivados na Junta Comercial do Estado de São Paulo, documentação de funcionários e bibliografia especializada. A partir da análise minuciosa das fontes, observou-se que houve um movimento comum na maioria das indústrias estudadas: a transformação de uma indústria inicialmente de capital fechado para Sociedades Anônimas; essa mudança na constituição abria a possibilidade de aumento do capital por meio da emissão de ações e a contratação de empréstimos em instituições bancárias com taxas reduzidas Isso porque as Sociedades Anônimas têm como exigência legal a publicação 


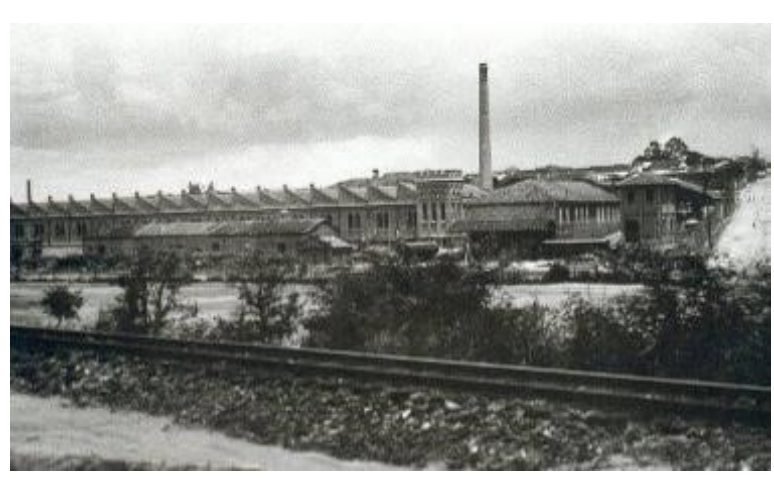

Figura 1. Nossa Senhora da Ponte, 1924. Foto: Pedro Neves dos Santos, acervo Museu Histórico Sorocabano.

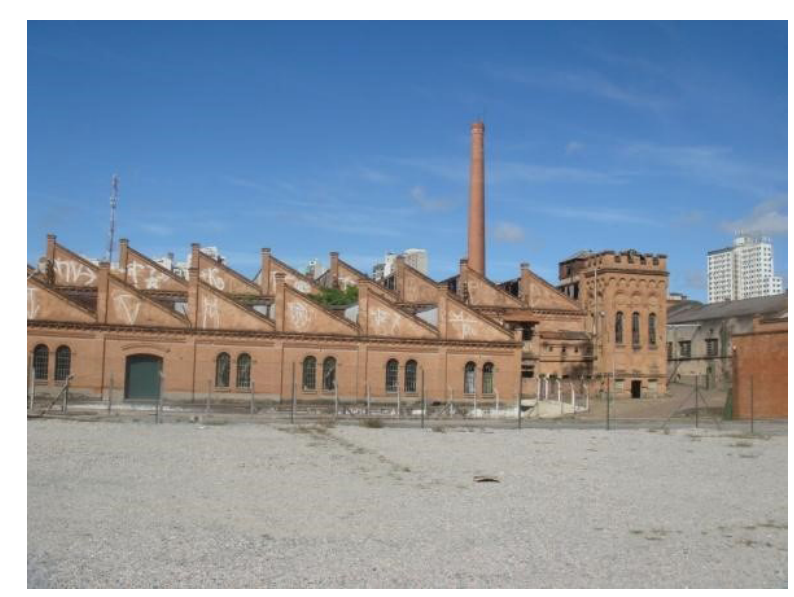

Figura 2. Fábrica desativada. Foto: Deborah Neves, 2010. anual de balanços realizados após auditorias rigorosas, conferindo maior segurança e transparência acerca da saúde financeira da empresa. Dessa forma, a instituição bancária pode ofertar crédito a uma taxa de acordo com seus resultados e capacidade de pagamento. A forma da constituição das empresas foi determinante para sua perenidade ao longo das décadas, decorrente da capacidade de ampliação da produção, de modernização das instalações e incremento tecnológico, tornando o estado de São Paulo a maior potência industrial do país.

Passa-se agora a um resumo da pesquisa do estudo em conjunto empreendido pelo GEl entre os anos de 2010 e 2014, resultando no tombamento de quatro das seis instalações industriais têxteis analisadas. Saliente-se que todos os processos estão na sede da UPPH e possuem acesso público, mediante solicitação e agendamento.

\section{Processo 58349/08 - Fábrica Têxtil Nossa Se- nhora da Ponte - Sorocaba (1881)}

Mais antiga entre as unidades estudadas, fundada por Manuel José da Fonseca, a fábrica representa uma mudança importante na tecnologia têxtil ao ser a pioneira no Estado em utilizar algodão herbáceo para a fiação de tecidos, no auge da Guerra de Secessão. A fábrica foi instalada estrategicamente às margens da linha da Estrada de Ferro Sorocabana e do córrego Supiriri, ga- rantindo escoamento da produção e água para o funcionamento de caldeiras e bomba hidráulica, cujas máquinas foram importadas de Manchester da Curtis Sons \& Co.

A mão de obra era predominante de mulheres e crianças, por serem de menor custo, que fabricavam tecidos mais rústicos como morins, brins grossos com variedades de riscados e xadrezes, pois ainda não contavam com estamparias.

A análise em conjunto das tecelagens apontou que dentro de critérios pensados em torno de potencial energético, mão de obra e capital, a Nossa Senhora da Ponte talvez não tenha sido das mais importantes indústrias do Estado e nem mesmo em Sorocaba, já que foi ofuscada pelo desempenho espetacular, do ponto de vista econômico, da S.A. Votorantim e mesmo da Fábrica de Tecidos Santa Rosália. Todavia, pensando no tempo presente e mirando o passado, a Nossa Senhora da Ponte é a instalação industrial que se mantém mais íntegra e que mantém ímpar relação com a paisagem da cidade de Sorocaba - lindeira à ferrovia, cujo complexo foi tombado em 2018. Hoje, a fábrica está ocupada pelo Shopping Pátio Cianê, em referência ao grupo empresarial que adquiriu a Fábrica Nossa Senhora da Ponte na década de 1940. O tombamento foi homologado em 2017, pela Resolução SC-63 de 19/12/2017, publicado no Diário Oficial de 23/12/2017, pp.56-57. 
Processo 59254/09 - Fábrica Brasital e Vila de Operários - Societá per l'Exportazione e per I'Industria Italo Americana - São Roque (1890)

Fundada pelo italiano Enrico Dell'Acqua, a empresa foi a pioneira no município de São Roque, em terreno de propriedade do agricultor de algodão Manuel Lopes Oliveira, mesmo fornecedor de algodão da Fábrica Nossa Senhora da Ponte de Sorocaba. Instalada no sopé de uma colina, a fábrica estava servida por água do córrego Aracaí, que canalizado, passa pelo interior da planta da fábrica, alimentando uma turbina e um motor a vapor - importados de Milão e ainda presentes no edifício - que geravam força motriz para todos os teares. O sistema hidráulico também alimenta um sofisticado programa de combate a incêndios construído com equipamentos ingleses da empresa Mather \& Platt Co. de Manchester, Inglaterra.

A solução arquitetônica e de engenharia são os grandes destaques desta indústria que teve mão de obra constituída majoritariamente por italianos e possuía apenas tecelagem, sem setor de fiação. Esse sistema de movimentação por turbina d'água é similar ao presente no Moinho e Fábrica de Algodão New Lanark, na Escócia, cuja construção data do século XVIII, considerado hoje Patrimônio Histórico Mundial, e faz da fábrica de São Roque um exemplar único no Estado de São Paulo, e possivelmente no Brasil. Recentemente, a fábrica teve o assoalho em madeira recuperado e com uso parcial das edificações por equipamentos da Prefeitura.

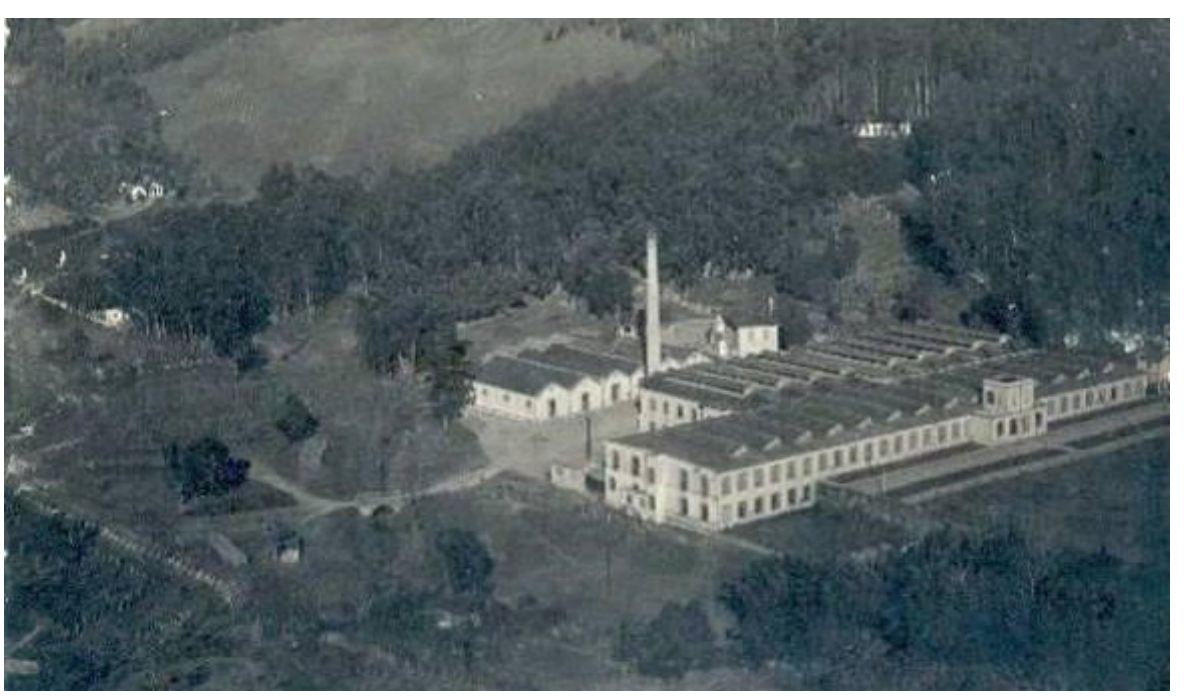

Figura 3. Imagem oblíqua aérea. Foto: IGC, 1939/1940.

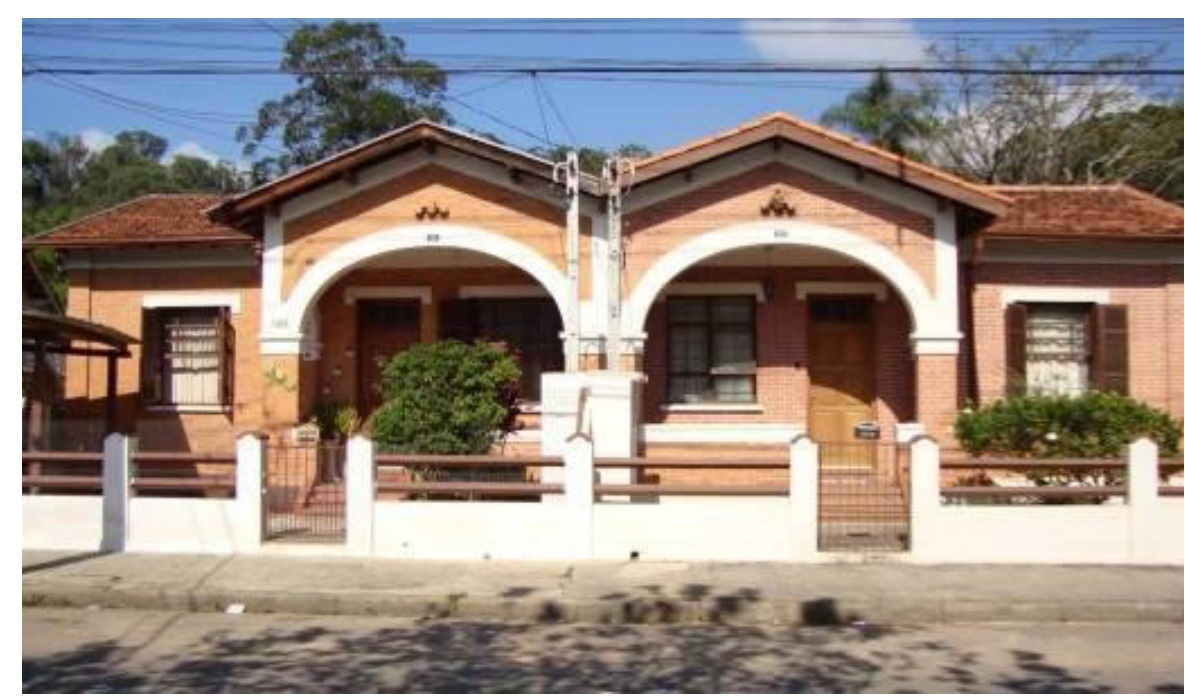

Figura 4. Uma dupla de casas da Vila. Foto: Deborah Neves, 2014 


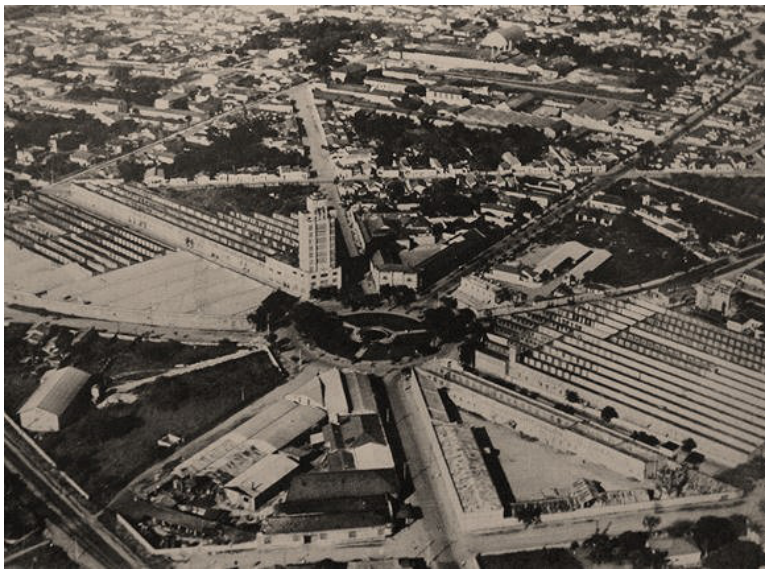

Figura 5. Vista da CTI, década de 1960. Disponível em: http://www.almanaqueurupes.com.br/portal/textos/ colunistas/o-pu-e-o-puxao-de-orelhas/

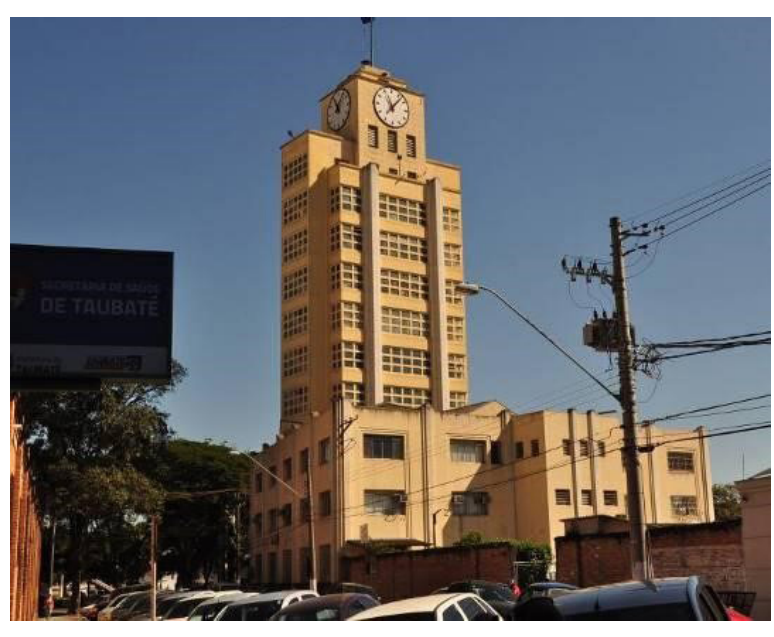

Figura 6. Prédio de escritórios. Foto: Deborah Neves, 2012
Outro destaque da Brasital de São Roque é a presença íntegra de sua vila operária, construída entre as décadas de 1940 e 1950, habitadas hoje por descendentes dos trabalhadores da fábrica e em excelente estado de conservação.

O tombamento foi decidido pelo CONDEPHAAT em 2014 e ainda aguarda homologação pelo Secretário da Cultura.

\section{Processo 30006/92 - Companhia Taubaté Industrial - Taubaté (1891)}

Fundada como uma Sociedade por Cotas no ano de 1891, a empresa se destaca como de grande porte, com capital oriundo de setores diversos da sociedade e especialmente por estar em uma cidade essencialmente agrícola, com posição estratégica entre o litoral Norte, a cidade de São Paulo e Rio de Janeiro, servida pela Estrada de Ferro Central do Brasil.

Teve à frente da empresa Félix Guisard, homem de visão empreendedora que buscou a inovação tecnológica - com a construção da planta da fábrica de forma radial para a otimização do processo, a construção de uma hidrelétrica própria para autossuficiência energética e a importação de maquinário alemão também para a geração de energia - bem como técnicas de gestão empresarial, como a administração de pessoal baseadas em uma visão de bem-estar social do trabalhador. Em função da fábrica, equipamentos sociais foram construídos, como escola, posto de saúde, estádio de futebol e uma colônia de férias em Ubatuba, litoral Norte de São Paulo, além de casas para parte de seus empregados.

A disposição de seus edifícios seguiu uma lógica de desenvolvimento racional, seguindo preceitos de urbanismo. Ainda que a implantação da fábrica tenha ocorrido numa zona suburbana, mas próxima da cidade - ao lado da linha férrea da Central do Brasil e não muito distante da Estação da cidade - essa região inverteu a lógica da importância central. Atualmente, o edifício de escritórios de traços art decó, construído na década de $1940 \mathrm{~m}$, é a sede da Prefeitura de Taubaté Essa linguagem se refletiu na fachada de outros três edifícios mais antigos, que tiveram acréscimo de frisos verticais, criando unidade visual na praça circular que leva o nome do diretor Felix Guisard. Os edifícios mais antigos têm características manchesterianas e em tijolos aparentes. Dois blocos foram demolidos na década de 1970. Além de equipamentos da Prefeitura, dois edifícios pertencem à Universidade de Taubaté (Unitau), que sediou a segunda edição do Docomomo, realizado no ano de 2000.

O tombamento foi homologado em 2017, pela Resolução SC-69 de 19/12/2017, publicado no Diário Oficial de 23/12/2017, pp.54-55. 


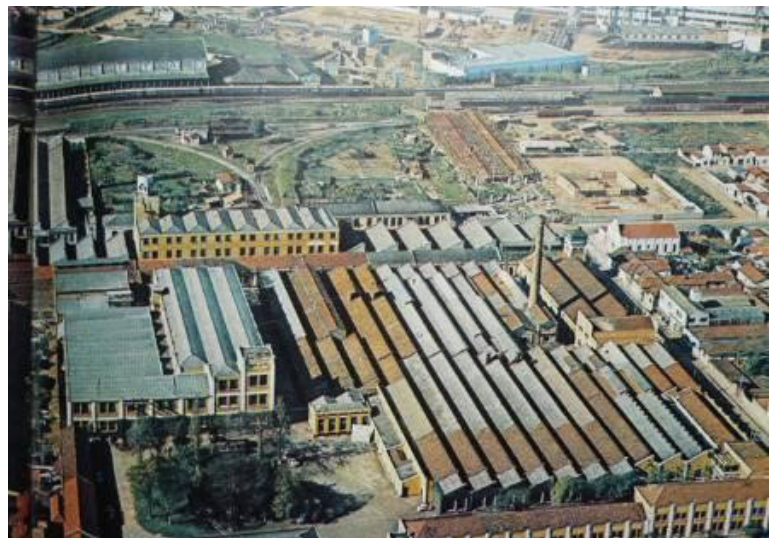

Figura 7. Imagem aérea da fábrica Argos. Foto: Mingo Gasparai, publicada em Revista Manchete, n.802, 02 set. 1967

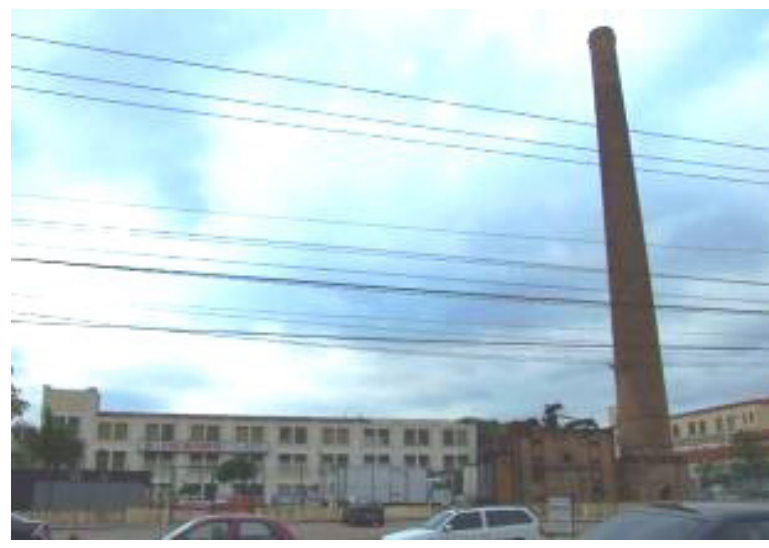

Figura 8. Perspectiva dos remanescentes da Argos. Foto: Deborah Neves, 2012
Processo 31605/94 - Argos Industrial - Jundiaí (1913)

Inaugurada em 1904 sob o capital de empresários italianos (Aleardo Borin e Luiz Trevisioli) e alemão (Ernest Diederichsen), a Argos se instalou na área da cidade de Jundiaí servida pela São Paulo Railway, Companhia Ituana e Companhia Paulista e por um córrego, além de estar servida com energia elétrica. A cidade já tinha se estabelecido como um importante polo da indústria têxtil no estado de São Paulo.

A construção da fábrica ocorreu de forma contínua, especialmente na década de 1910 e com nova ampliação na década de 1940, o que configura dois aspectos físicos bem marcados temporalmente. Os edifícios mais primitivos são erigidos com tijolos autoportante e apresentam sheds em ritmo constante. Já os edifícios mais recentes e justamente mais preservados, são forjados em concreto e trazem elementos que remetem ao art decó. É importante salientar, no entanto, que parte significativa da edificação mais antiga foi demolida pela Prefeitura em meados dos anos 1990, sob a justificativa de ampliação viária e urbanização da área, que seria convertida em uma praça. No entanto, a duplicação da avenida não avançou sobre a área do terreno resultante da demolição e a praça nunca foi construída, res- tando uma ampla área de estacionamento, ornamentada pela chaminé da caldeira de tingimento de tecidos.

A Argos se destaca na paisagem por seu grande porte e ocupação de vasta dimensão e é responsável por boa parte do traçado urbano do bairro da Vila Arens. Suas três vilas operárias se espraiam por seis quarteirões e mantém características ainda passíveis de identificação como conjunto. Destaque também para a presença dos edifícios que abrigaram a creche e a escola para os filhos dos funcionários, que hoje, pertencem à Prefeitura e continuam sendo utilizados com finalidades educacionais.

Ainda que o indicativo da área técnica tenha sido o de tombamento da edificação, da creche e de parte das casas que compõem a vila operária, o Conselho entendeu que o pedido deveria ser arquivado, já que parte da fábrica fora demolida. No entanto, houve recurso por parte de uma munícipe que resultou na reversão da decisão anterior. Saliente-se que se trata do último exemplar fabril têxtil da cidade de Jundiaí, de extrema importância no Estado.

O tombamento foi homologado em 2017, pela Resolução SC-65 de 19/12/2017, publicado no Diário Oficial de 23/12/2017, pp.57-58. 


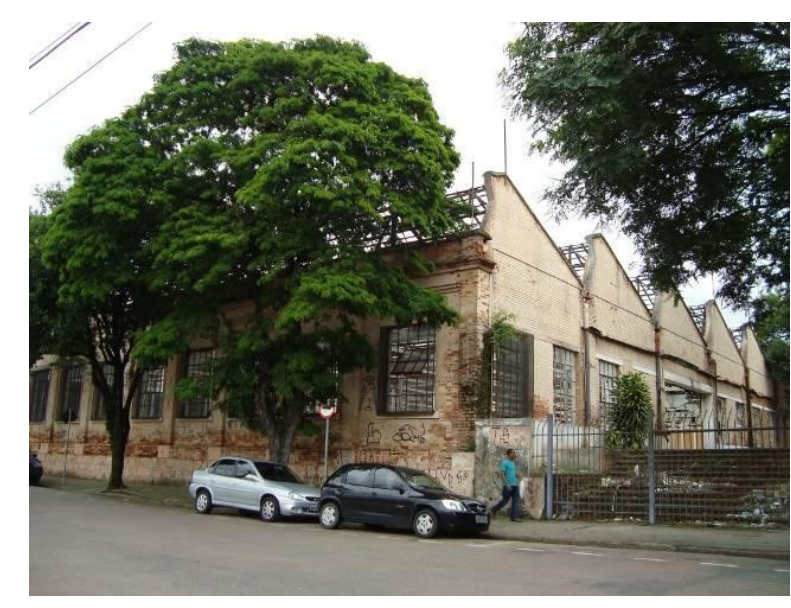

Figura 9. Vista da fachada frontal e lateral. Foto: José A.C.Zagato, 2011.

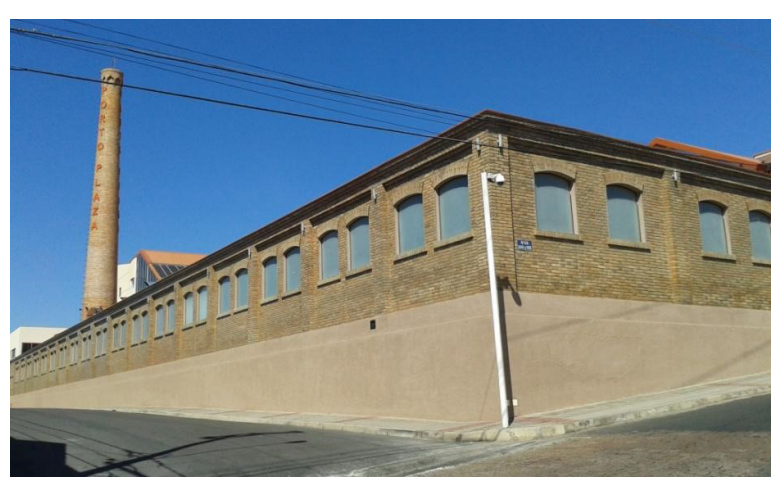

Figura 10. Vista da Lateral da Tecelagem. Foto: Deborah Neves, 2013.
Processo 65641/11 - Fábrica Japy, Jundiaí (1913)

Tendo como um de seus fundadores o empresário e Senador Antônio Lacerda Franco, a Fábrica Japy S.A. teve inauguração, como sua vizinha Argos, já na década de 1910, momento em que as tecelagens se consolidavam como equipamento industrial rentável em decorrência da substituição de importação, agravada pela Primeira grande Guerra. Fundada já como uma Sociedade Anônima, a empresa se caracterizou por estar ligada a um grupo que controlava outras empresas do ramo de serviços e da indústria, conformando um conglomerado.

A edificação, no entanto, foi construída anteriormente à constituição da sociedade - não foi possível identificar com exatidão -, provavelmente em 1913, uma vez que há registro de contrato de fornecimento de água entre a fábrica e a Câmara Municipal de Jundiaí datado de 22/07/1913, e caracterizava-se pela extensão em um vasto lote próximo à ferrovia e pelo pavimento único em tijolos autoportantes marcado pelo ritmo dos sheds. Seu despojamento e simplicidade são justificados pelo fato de se tratar apenas de tecelagem, sem setor de fiação, incomum para uma empresa do porte da Japy.

A fábrica ficou especialmente marcada pela gestão de José João Abdalla a partir da década de 1940, conhecido vulgarmente como "o mau pa- trão", em decorrência da sonegação dos direitos trabalhistas de seus empregados e o não cumprimento de suas obrigações financeiras, além do uso da máquina pública em benefício privado. $\mathrm{O}$ fim das atividades da fábrica é decorrente de sua má administração, na década de 1970, quando o prédio passou a ser ocupado por supermercados, até que em 2011 uma construtora de edifícios residenciais comprou o terreno e demoliu parte significativa da fábrica - antes da instrução do pedido de tombamento feito pelo GEI - uma das razões pela qual se indicou o arquivamento do pedido de tombamento.

\section{Processo 47329/03 - Fábrica de Tecidos Nossa Senhora Mãe dos Homens, Porto Feliz, (1924)}

A Fábrica de Tecidos Nossa Senhora Mãe dos Homens foi fundada no ano de 1924, reunindo nesta Sociedade Anônima vários pequenos acionistas e dois principais: Antônio Emygdio de Barros e José Emygdio de Barros, políticos conhecidos do estado de São Paulo.

Não era das maiores indústrias do Estado, embora a única de tecidos na cidade de Porto Feliz, mas por seu capital e força de produção é considerada uma empresa de grande porte. Não há surpresa nesse fato, já que os principais acionistas eram família Emygdio de Barros: Antônio e seu pai, José, além de grandes industriais como Sylvio Brand Correa (um dos fundadores da Construtora Camargo Correa), e até mesmo 
empresas (como Kortenhaus Stummel \& Comp. - maquinas para indústria têxtil; e Elias João Habice \& Filhos - comerciante, representante da Westinghouse no Brasil, sócios da Cooperativa de Crédito). Outros acionistas individuais como Antonio Martins de Sampaio, Francisco Souza Moraes, Antônio Eulálio de Camargo, as famílias Pires de Almeida e Almeida Portella eram ligados ao cultivo de algodão. Além disso, grande parte dos acionistas pertencia ao Partido Republicano Paulista - incluindo José Augusto Pereira de Rezende, cunhado de Antonio Emydgio de Barros e Presidente do PRP na região de Botucatu. $O$ PRP foi o partido que havia colocado Prudente de Moraes, Campos Salles, Rodrigues Alves e Washington Luís na presidência do Brasil.

Tratamos aqui, portanto, de uma empresa que nasce com o capital da elite política e financeira do interior de São Paulo, que não dependida da Fábrica de Tecidos para sua subsistência. Tratava-se de uma atividade que se tornara comercialmente rentável nas primeiras décadas do século $X X$ e por isso atraiu o investimento dessas pessoas. A Fábrica agregava o interesse dos acionistas, diretamente interessados: havia produtores de algodão da cidade, importadores de máquinas, banqueiros, capitalistas e políticos. Não à toa, a Fábrica de Tecidos contou com diversos subsídios da Câmara de Vereadores de Porto Feliz na aquisição de máquinas e até na isenção de impostos.
Chama atenção justamente o fato de uma fábrica de tecidos ter sido fundada por grandes possuidores de capital, em uma cidade sem tradição fabril e pouca expressão na cultura algodoeira em um momento em que a indústria têxtil, como um todo, encontrava-se em crise. Vale também pesquisar a motivação da junção de capitalistas tão importantes nesse empreendimento e as relações de poder que esses possuíam com entes públicos e outros privados, além das conexões políticas importantes. Além de ter nomes importantes do PRP, a Fábrica de Tecidos Nossa Senhora Mãe dos Homens aglomerou um futuro governador - Adhemar de Barros - e a família de outro - Luiz Antônio Fleury Filho. As teias empresariais que os principais sócios faziam parte é também um ponto importante e que deveria ser analisado com mais profundidade.

Sua planta é simples, dividida em três blocos com ruas internas, que hoje formam as ruas da cidade de Porto Feliz. Nesse ponto, em muito lembra a configuração da tecelagem de Seda Italo-Brasileira, localizada no bairro do Brás nessa capital, embora em muito menor escala. Atualmente um shopping center está instalado no edifício que serviu à tecelagem, um mercado no que foi a fiação e a sede da Prefeitura no prédio da antiga Cooperativa de funcionários.

Devido ao não enquadramento nos critérios de avaliação, foi indicado o arquivamento da proposta de tombamento e a cobrança de multa 
para a proprietária do shopping, que descaracterizou fisicamente a fábrica, trazendo prejuízos à paisagem da cidade e ao patrimônio cultural.

\section{Conclusão}

O balanço que é feito é que a preservação de quatro das seis fábricas estudadas traz importante acréscimo à história paulista, que ganha exemplares materiais de extrema relevância para a arquitetura e especialmente para a história do estado, sem impedir seu uso por novas atividades.

A partir do tombamento, o compromisso das partes - Estado e proprietários -deve ser a garantia da manutenção destes edifícios não apenas como exemplares individuais e isolados, mas a compreensão deles como parte de um complexo sistema que estruturou decisivamente a economia do país e só fazem sentido se lidos dentro da lógica de conjunto. Isso porque cada um reserva peculiaridades e revela distintas faces do empreendimento têxtil no estado, constituindo-se como importantes documentos para a compreensão da História, da Economia, da Arquitetura e do Urbanismo das cidades e, tomados em conjunto, do estado de São Paulo.
A consolidação de uma política de valorização e difusão do patrimônio em toda a sua potência certamente é um desafio que se impõe com mais grandeza que o próprio ato do tombamento em si, insuficiente para garantir sua integridade e importância para a sociedade. Faz-se necessário o estabelecimento de políticas públicas e privadas de reconhecimento e valorização, como o estabelecimento de rotas culturais, por exemplo, além de um compromisso em incluir tais locais no planejamento das cidades. O tombamento deve ser encarado como um instrumento aliado que garante o respeito à edificação e à sua capacidade de múltiplas evocações, superando a equivocada ideia de "congelamento", construída no imaginário comum por desconhecimento da legislação e mesmo por um afastamento do órgão de preservação das prefeituras, que vem sendo corrigido ao longo dos anos por meio de oficinas e atendimentos técnicos.

\section{Referências}

BIONDI, Luigi. A greve geral de 1917 em São Paulo e a imigração italiana: novas perspectivas. Cadernos AEL, v. 15 n²7, 2009. Disponível em https://www.ifch.unicamp.br/ojs/index.php/ ael/article/view/2577/1987, acessado em 10 jun. 2014. 
BELANGA, Tatiana Pedro Colla. Financiamento, lucratividade e desempenho industrial na grande depressão: empresas têxteis em São Paulo - 1928/1933. Cadernos da FACECA, Campinas, v. 15, n. 1, p. 49-62, jan./jun. 2006, disponível em http://www.puc-campinas.edu.br/centros/ cea/sites/revista/conteudo/pdf/vol15_n1_financiamento.pdf, acessado em 11 jan.2012.

DE DECCA, Edgar Salvadori. 1930, o silêncio dos vencidos: memória, história e revolução. 6 Edição. São Paulo: Brasiliense, 2004.

DEAN, Warren. A industrialização de São Paulo. São Paulo: Editora da Universidade de São Paulo, 1971.

HARDMAN, Francisco Foot; LEONARDI, Victor. História da Indústria e do trabalho no Brasil

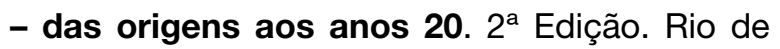
Janeiro: Editora Atica, 1991

LOUREIRO, Felipe Pereira. Resenha de "A tessitura dos direitos: patrões e empregados na Justiça do Trabalho, 1953-1964.", de Larissa Rosa Correa. Revista Perseu, n7, ano 5, 2011. Disponível em http://revistaperseu.fpabramo.org. br/index.php/revista-perseu/article/view/44/18. Acesso em: 21 ago. 2018.
LOUREIRO, Felipe Pereira. Nos fios de uma trama esquecida: a indústria têxtil paulista nas décadas pós-Depressão (1929-1950). Dissertação de Mestrado em História. São Paulo, USP, 2006.

MOTA, Carlos Guilherme. São Paulo: exercício de memória. Estudos. Avançados, Ago 2003, vol.17, $n^{\circ}$ 48. Disponível em http://www.scielo.br/ pdf/ea/v17n48/v17n48a20.pdf, acessado em 23 ago. 2019.

PRADO JUNIOR, Caio. História Econômica do Brasil. 20ª Edição. São Paulo: Editora Brasiliense, 2012.

RIBEIRO, Maria Alice Rosa. Condições de trabalho na indústria têxtil paulista (1870-1930). São Paulo: Editora Hucitec/Editora da Unicamp, 1988.

SANT'ANNA, Nuto. São Paulo Histórico. Aspectos, Lendas e Costumes. Volume 5. São Paulo: Departamento de Cultura da Prefeitura de São Paulo, 1944.

SÃO PAULO (Estado). CONDEPHAAT. Processo 30006/92. Estudo de tombamento da Cia. Taubaté Industrial, Taubaté. 
SÃO PAULO (Estado). CONDEPHAAT. Processo 31605/94. Estudo de tombamento da Argos Industrial S.A., Jundiaí.

SÃO PAULO (Estado). CONDEPHAAT. Processo 47329/03. Estudo de tombamento da Fábrica de Tecidos Nossa Senhora Mãe dos Homens, Porto Feliz.

SÃO PAULO (Estado). CONDEPHAAT. Processo 58349/08. Estudo de tombamento da Fábrica Têxtil Nossa Senhora da Ponte, Sorocaba.
SÃO PAULO (Estado). CONDEPHAAT. Processo 59254/09. Estudo de tombamento da Fábrica Brasital e Vila de Operários, São Roque.

SÃO PAULO (Estado). CONDEPHAAT. Processo 65641/11. Estudo de tombamento da Fábrica de Tecelagem Japi, Jundiaí.

STEIN, Stanley. Origens e Evolução da indústria têxtil no Brasil - 1850-1950. Rio de Janeiro: Campus, 1979.

TEIXEIRA, Francisco. A história da indústria têxtil paulista. São Paulo: Artemeios, 2007. 